\title{
Study of the Importance of MPPT Algorithm for Photovoltaic Systems under Abrupt Change in Irradiance and Temperature Conditions
}

\author{
DEEPTHI PILAKKAT and S.KANTHALAKSHMI \\ Dept. of Electrical and Electronics Engineering, \\ PSG College of Technology, \\ Coimbatore 641004, \\ INDIA
}

\begin{abstract}
In order to understand the importance of MPPT algorithms, modeling and simulation of a PV system with and without MPPT algorithm using MATLAB/SIMULINK under different irradiance and temperature variations are analyzed in this chapter. The MPPT technique used is Incremental Conductance (INC) algorithm. First of all, the P-V (power-voltage) and I-V (Current-Voltage) characteristics are noticed for different values of solar irradiance while keeping the cell temperature constant. Later on, for different temperature values with constant irradiance levels the characteristics of PV panel has been studied. The effect of temperature and irradiance on power, current, voltage and duty ratio of the PV system with and without INC MPPT algorithm is analyzed for understanding the importance of MPPT techniques in PV systems.
\end{abstract}

Key-Words: - Incremental Conductance Algorithm (INC), Maximum Power Point Tracking (MPPT), Renewable energy systems, Solar PV systems, MATLAB/SIMULINK.

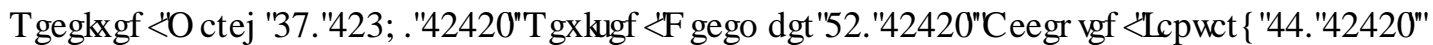

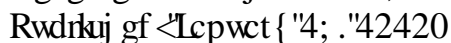

\section{Introduction}

As the increase in global warming and traditional non - renewable energy sources such as fossil fuels are declining, sustainable energy sources such as solar - oriented, wind, geothermal and so on are gaining more consideration as alternative sources of energy. The solar photovoltaic (PV) energy has been widely used in many applications among renewable energy sources. The focal points, for example, direct electric power structure, simple support, no noise, and so on expands the usage of solar energy resources[1]. With a huge increase in the use of non - conventional sources of energy, PV systems are increasingly being used in a few applications. However, addressing its nonlinear output characteristics, which vary with temperature and solar insolation, is a major challenge in using a PV source [2].

A PV panel comprises of huge number of solar based cells associated in series or parallel so as to get the required current and voltage. A solar cell's voltage, current or resistance may vary in light exposure. Excess electron - hole pairs are generated when a solar cell is illuminated and current flows through the electrically shortened $\mathrm{p}$ - $\mathrm{n}$ junction. In his paper, to extract maximum power from the solar panel, a solar PV system with INC MPPT algorithm is designed and simulated with the boost converter. The algorithm was analyzed in variations in irradiance and temperature levels for four different cases. It is shown that for changing atmospheric conditions, the MPPT tracks the maximum power point. A DC / DC converter is embedded between PV module and load to track the maximum power point for certain irradiance and climatic conditions [3].

\section{Incremental Conductance Algorithm}

One of the most frequently used conventional MPPT algorithm is the Incremental Conductance algorithm first proposed by Hussain et al. in 1995 [4]. The flowchart in Fig.1 describes the operation of INC.

So as to choose whether to increment or decrement the duty cycle, the incremental and instantaneous conductance are determined dependent on the voltage and current from the PV panel. In order to obtain incremental conductance, small voltage and current changes are measured, whereas instantaneous conductance is calculated by dividing panel current by panel voltage. These two values of parameters are continually updated and compared until MPP is reached. 


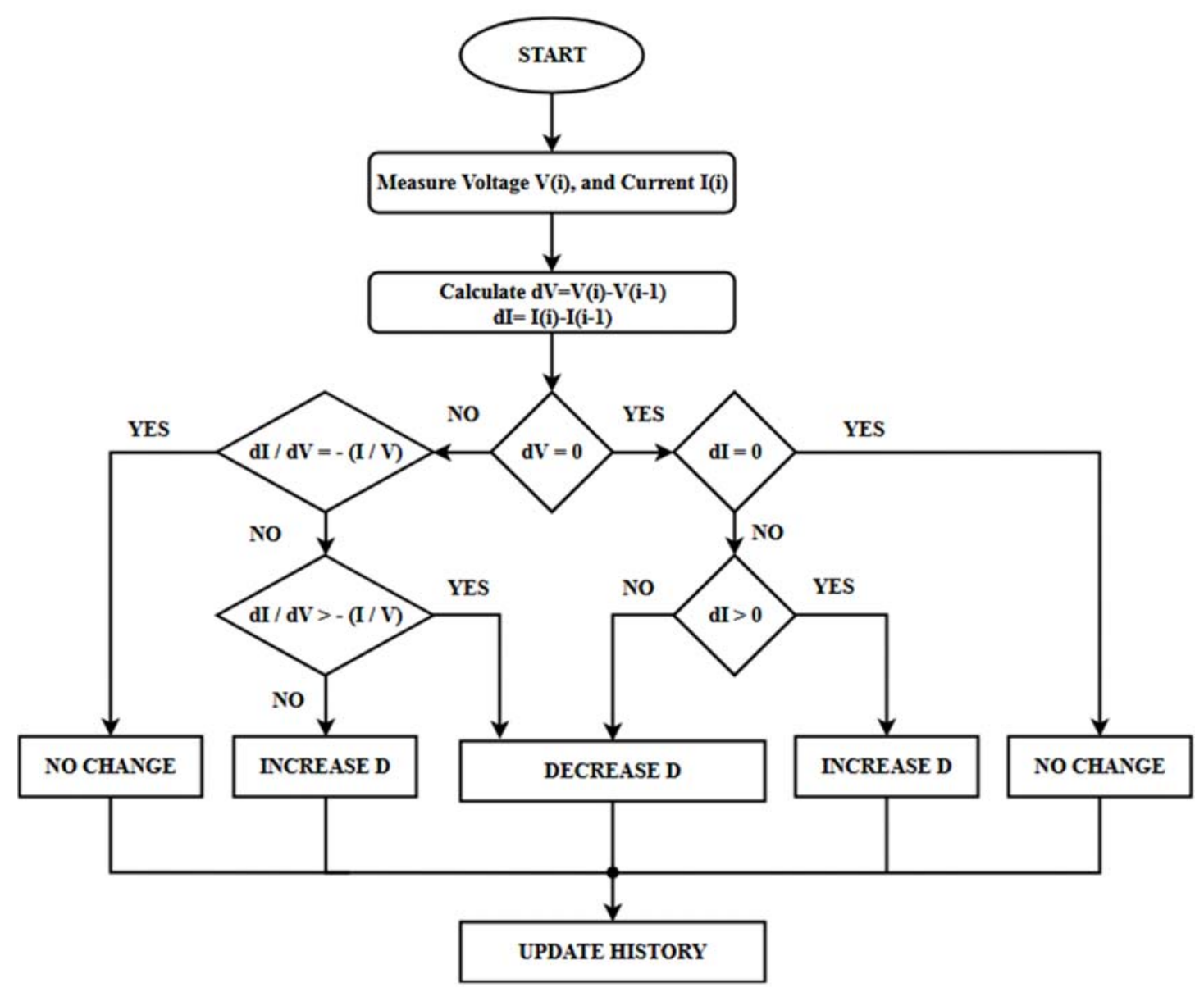

Fig.1 Flow chart of conventional INC algorithm

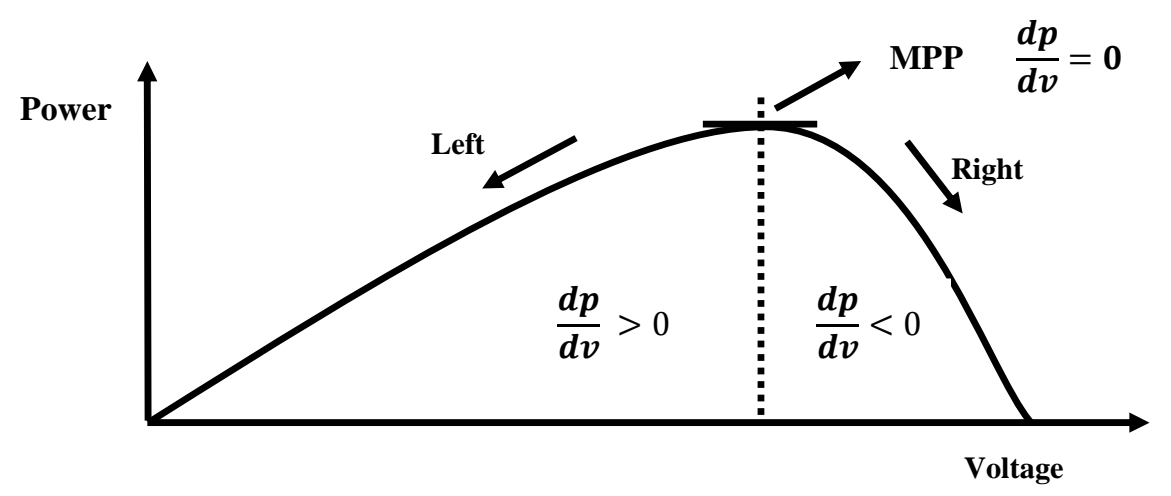

Fig.2 Basic idea of incremental conductance method on a P-V curve of a solar panel 
Fig.2 shows the basic principle of INC algorithm on the slope of a P-V curve of a solar panel. The idea behind INC algorithm resides on the fact that the derivative of the power with respect to the voltage becomes zero at MPP; negative at right side of MPP and positive at left side of MPP [5] [6]. The PV panel characteristics may undergo any one of the following three conditions during the initial operation.

$\frac{d P}{d V}=0 \quad$ at MPP

$\frac{d P}{d V}>0 \quad$ at left side of MPP

$\frac{d P}{d V}<0 \quad$ at right side of MPP

Because

$\frac{\mathrm{dP}}{\mathrm{dV}}=\frac{\mathrm{d}(\mathrm{VI})}{\mathrm{dV}}=\mathrm{I}+\mathrm{V} \frac{\mathrm{dI}}{\mathrm{dV}}$

Thus equations (2.1), (2.2) and (2.3) becomes

$\frac{d I}{d V}=-\left(\frac{I}{V}\right) \quad$ at MPP

$\frac{d I}{d V}>-\left(\frac{I}{V}\right) \quad$ left side of MPP

$\frac{d I}{d V}<-\left(\frac{I}{V}\right) \quad$ right side of MPP

The panel achieves its MPP when incremental conductance is equal to instantaneous conductance and will continue to function at MPP until a variation in current is considered. The current change is directly related to MPP and atmospheric circumstances. This method increases or decreases the duty cycle to operate the panel at MPP. When $\frac{\mathrm{dI}}{\mathrm{dV}}>-\left(\frac{\mathrm{I}}{\mathrm{V}}\right)$, the operating point of the panel will be at the left of MPP, thus to shift the panel's operating point close to MPP the voltage has to be increased. This is carried out by decreasing the duty cycle. Similarly, when $\frac{d I}{d V}<-\left(\frac{I}{V}\right)$, the operating point of the panel will be at the right of MPP, thus the duty cycle is to be increased so as to decrease the panel voltage. The operating voltage remains unaffected while operating at MPP.

\subsection{Pseudo Code for INC Method}

The pseudo code for INC method is as follows:

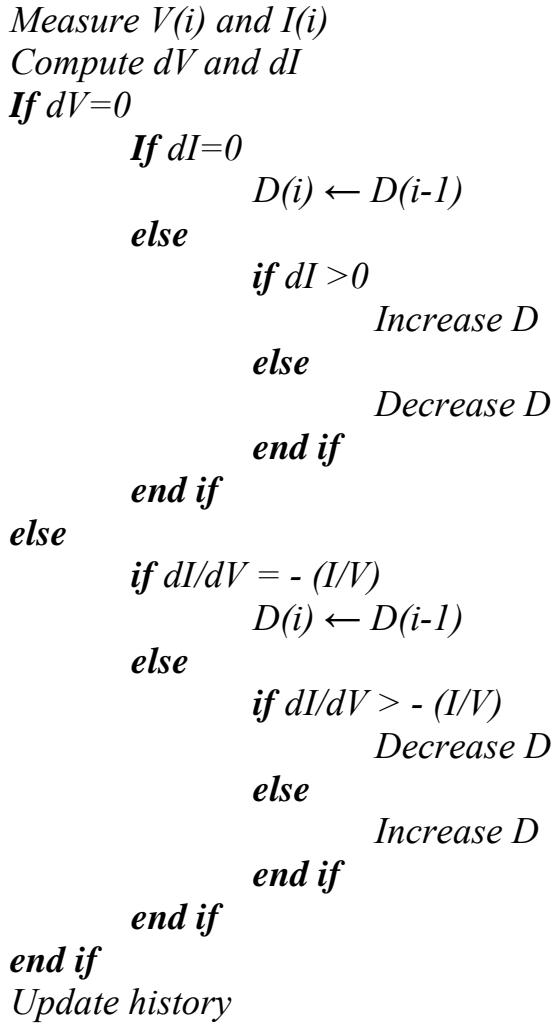

\section{Simulation Results}

This section describes about the simulation of PV module integrated with boost converter along with INC MPPT algorithm in MATLAB/SIMULINK environment. The VIKRAM SOLAR ELDORA$75 W$ PV panel is used for reference. Fig. 3 shows the simulation model of the PV system. The specifications of the panel are given in Table 1.

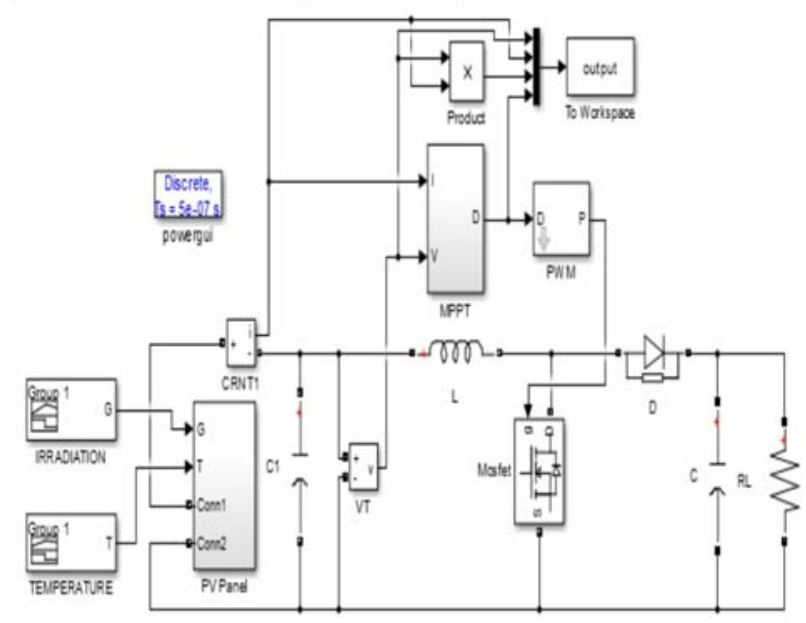

Fig. 3 Simulation model of the PV system 
TABLE 1. SPECIFICATIONS OF ELDORA-75 MODULE

\begin{tabular}{|c|c|}
\hline Description & Specification \\
\hline Maximum Power (Pmax) & $76.5 \mathrm{~W}$ \\
\hline Open circuit voltage (V $\left.\mathrm{V}_{\mathrm{OC}}\right)$ & $43.6 \mathrm{~V}$ \\
\hline Short circuit current (ISC) & $2.4 \mathrm{~A}$ \\
\hline $\begin{array}{c}\text { Maximum Power Point voltage } \\
\text { (Vmpp) }\end{array}$ & $34 \mathrm{~V}$ \\
\hline $\begin{array}{c}\text { Maximum Power Point Current } \\
\text { (Impp) }\end{array}$ & $2.25 \mathrm{~A}$ \\
\hline Module Efficiency & $10.10 \%$ \\
\hline $\begin{array}{c}\text { Short Circuit Current } \\
\text { Temperature Coefficient }\end{array}$ & $0.04 \% /{ }^{\circ} \mathrm{C}$ \\
\hline
\end{tabular}

Fig. 4(a), 4(b) and 4(c) show the PV panel current, voltage and power respectively at STC. The maximum power available at STC is $76.5 \mathrm{~W}$. $\mathrm{PV}$ panel current is $2.25 \mathrm{~A}$ and voltage is $34 \mathrm{~V}$.

The $\mathrm{P}-\mathrm{V}$ and $\mathrm{I}$ - V curve will change due to the variations in temperature and irradiance level and as a result the maximum power point will vary.

For this study, four different cases are considered to examine the effect of temperature and irradiation changes on the output characteristics of PV panels with and without MPPT algorithms.

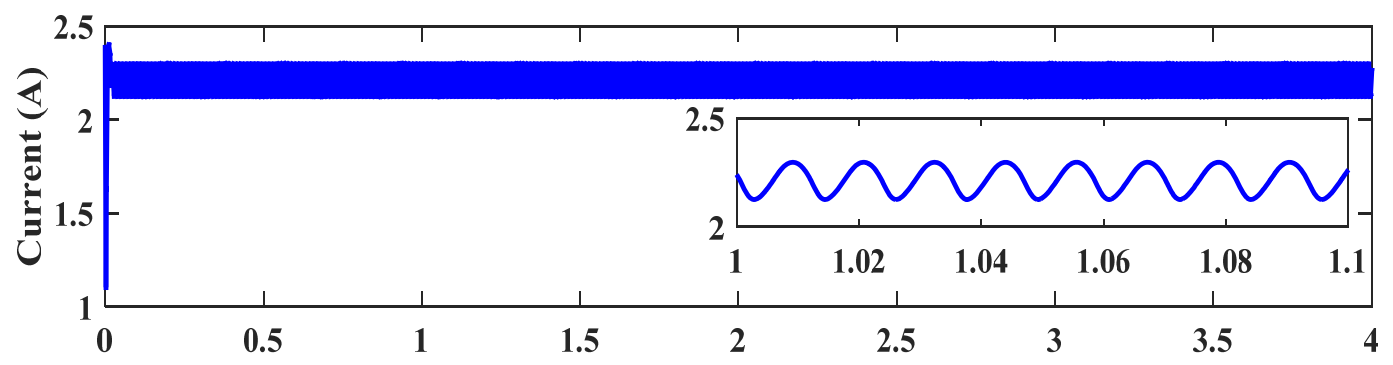

(a)

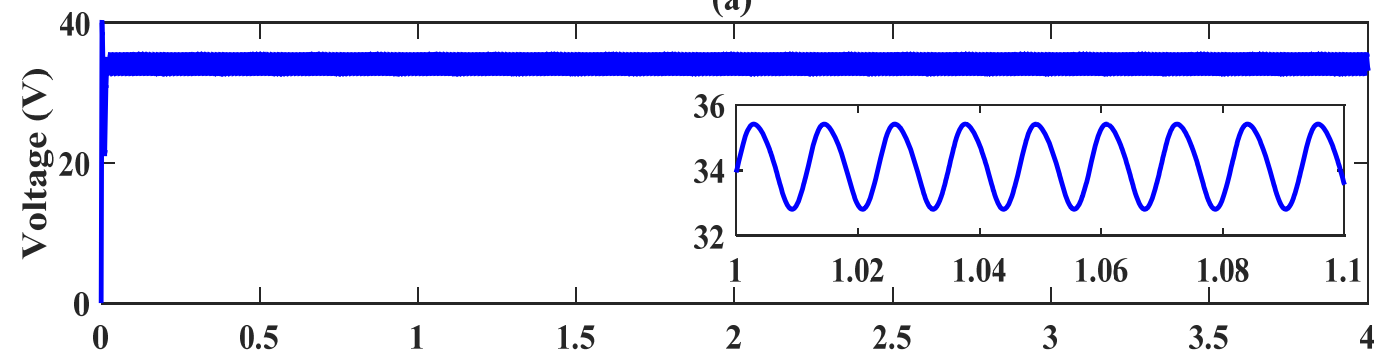

(b)

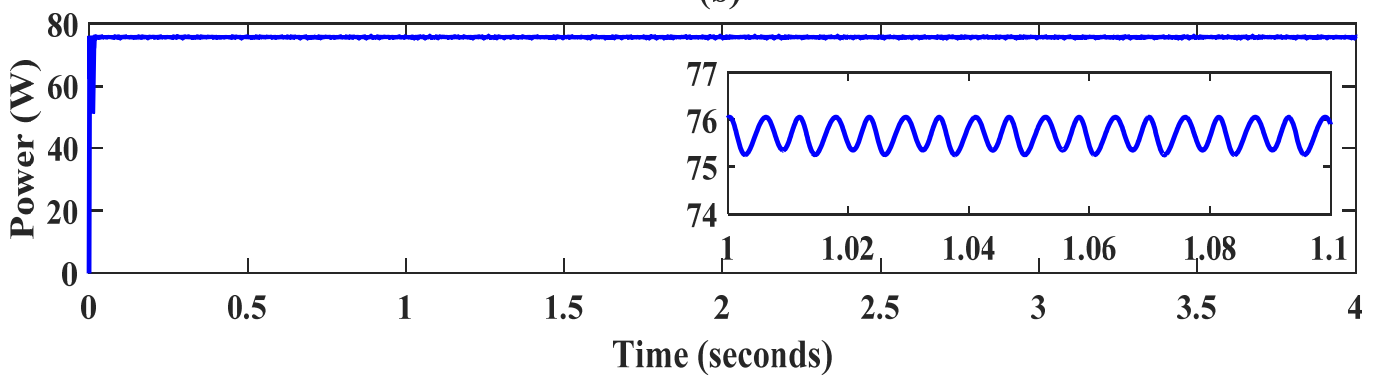

(c)

Fig. 4 (a) Output Current, (c) Output Voltage and

(d) Output Power of VIKRAM SOLAR ELDORA-75W solar panel at STC
3.1 Case I: Varying Irradiance and constant temperature

In case I, with a constant temperature of $25^{\circ} \mathrm{C}$, three different irradiances are taken. Fig. 5 shows the irradiance profile. 


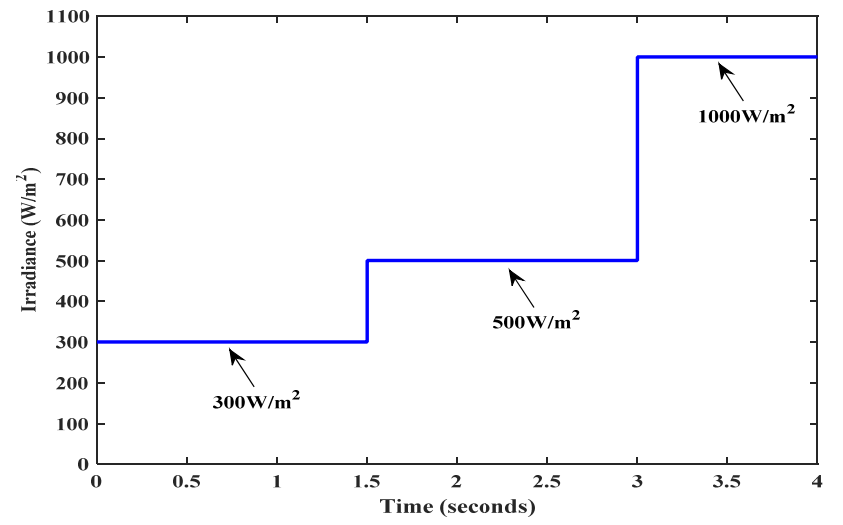

Fig. 5 Variation of irradiance with respect to time

From 0 to $1.5 \mathrm{~s} 300 \mathrm{~W} / \mathrm{m}^{2}$, from 1.5 to $3 \mathrm{~s}$ $500 \mathrm{~W} / \mathrm{m}^{2}$ and from 3 to $4 \mathrm{~s} 1000 \mathrm{~W} / \mathrm{m} 2$ are taken for analyzing solar panel performance with and without MPPT algorithm.

First, the working temperature of the cell is kept constant at $25^{\circ} \mathrm{C}$ and $\mathrm{P}-\mathrm{V}$ and $\mathrm{I}-\mathrm{V}$ curves are generated for different irradiance levels such as 300,

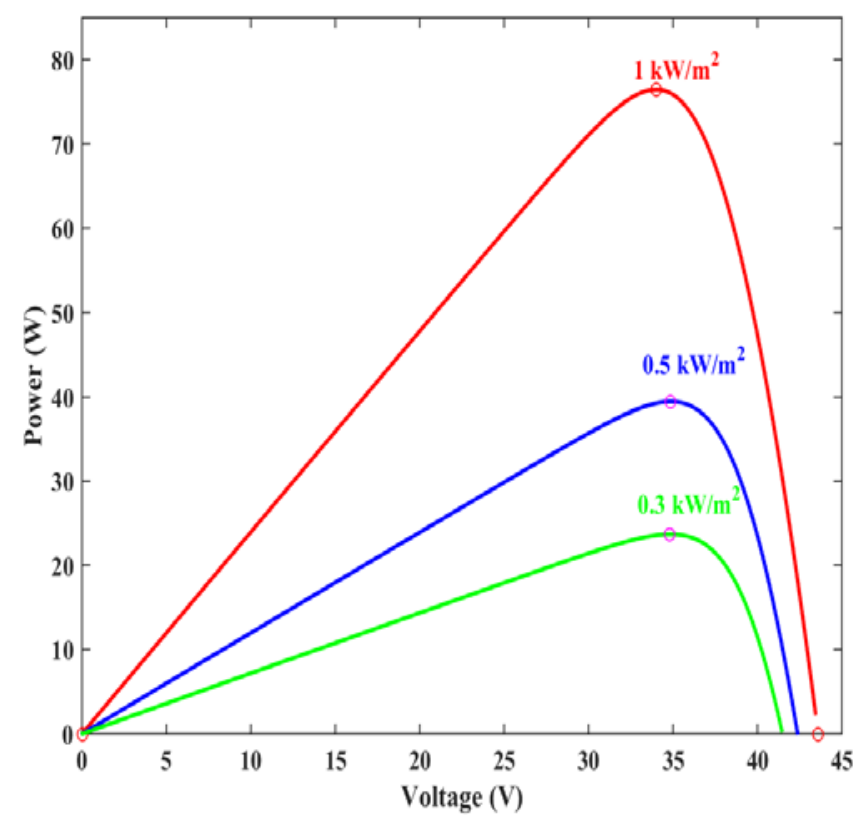

(a)
500 and 1000W/m2. Fig.6(a) and Fig. 6(b) shows the ELDORA-75W solar panel's P - V and I - V characteristics respectively for varying irradiation and constant temperature at $25^{\circ} \mathrm{C}$, respectively. Fig.6(a) shows that the output power decreases as the irradiance decreases. The short circuit current also decreased as the irradiation decreases as shown in Fig.6(b). It is clear from both $\mathrm{P}-\mathrm{V}$ and $\mathrm{I}-\mathrm{V}$ characteristics that the open circuit voltage of the PV panel decreases slightly as the irradiation decreases.

In Fig.7(a) and Fig.7(b) for a constant temperature of $25^{\circ} \mathrm{C}$, the current, voltage, power and duty ratio of PV panel with and without MPPT for different irradiance levels are shown. In the case of non - MPPT condition, a constant duty ratio of 0.6 is taken to evaluate the importance of the MPPT algorithm. The system with INC MPPT algorithm tracks the optimum duty cycle even if the input irradiance of the PV panel is changed. From Fig.7(b) it is seen that the maximum power tracked for $800 \mathrm{~W} / \mathrm{m}^{2}$ with MPPT is $37.9 \mathrm{~W}$.

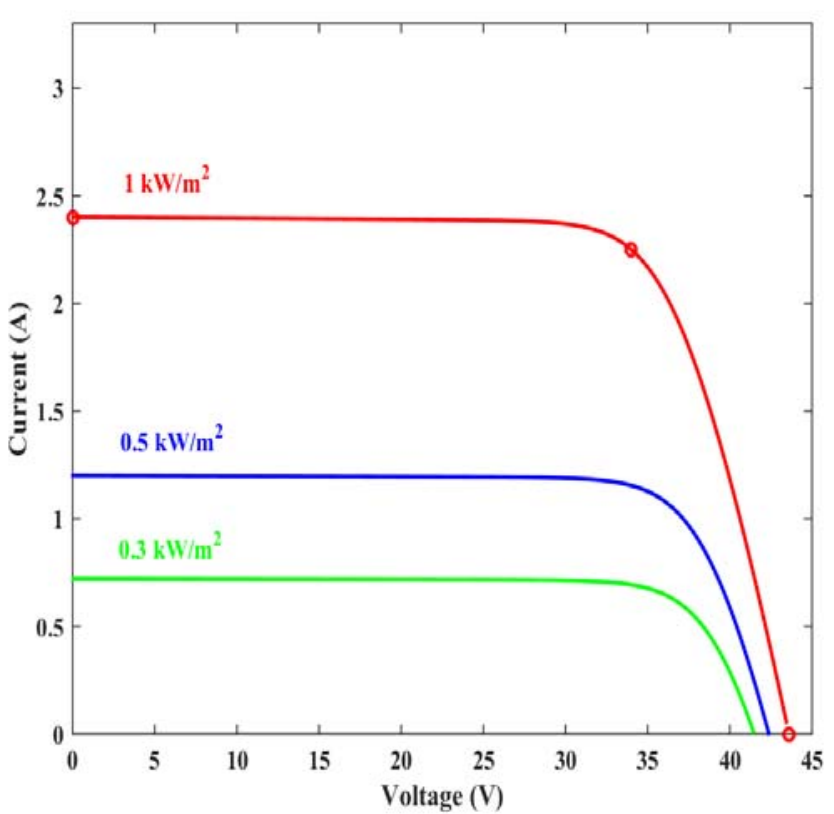

(b)

Fig.6 (a) P-V characteristics (b) I-V characteristics of PV panel at constant temperature of $25^{\circ} \mathrm{C}$ and varying irradiation 

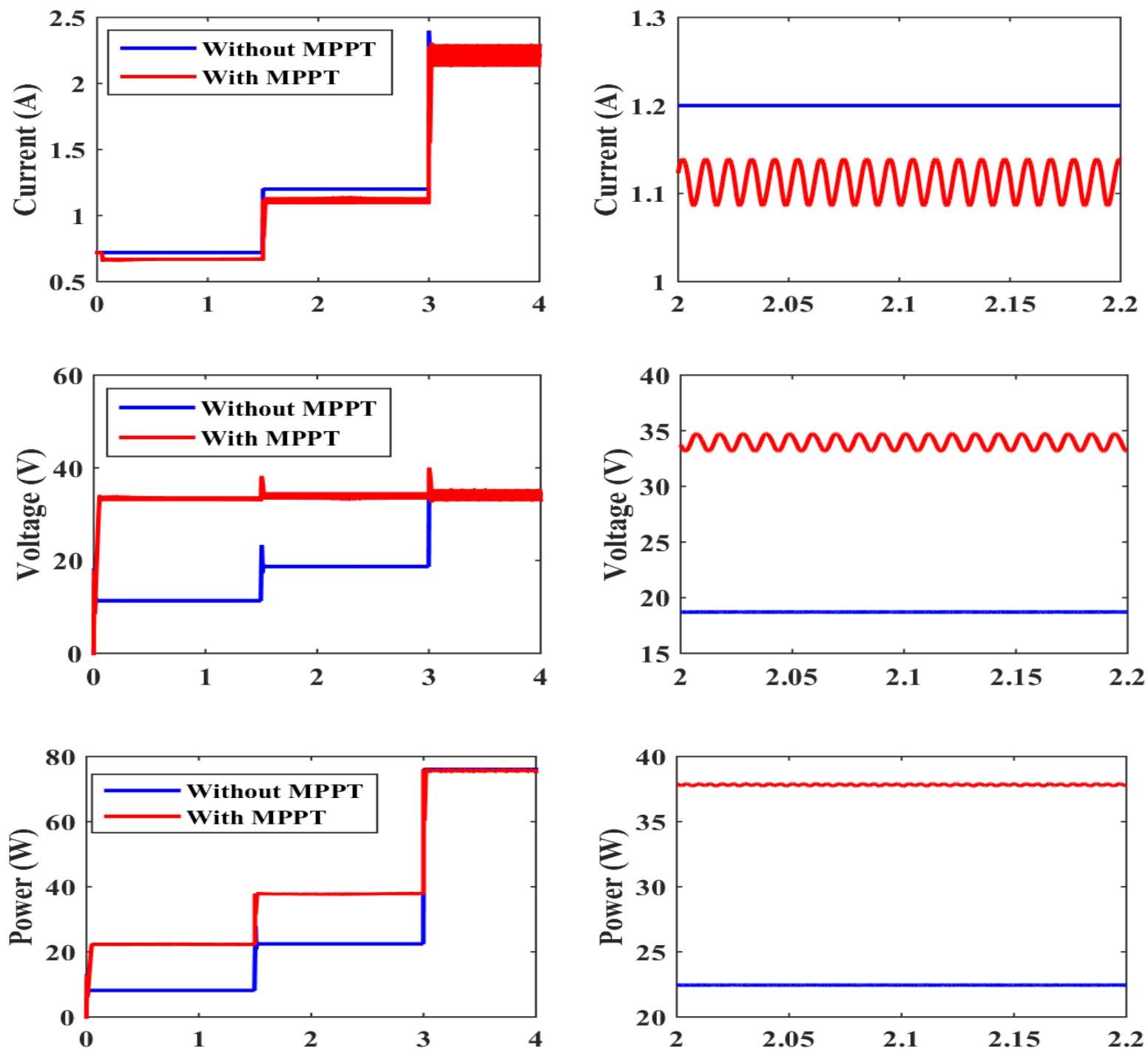

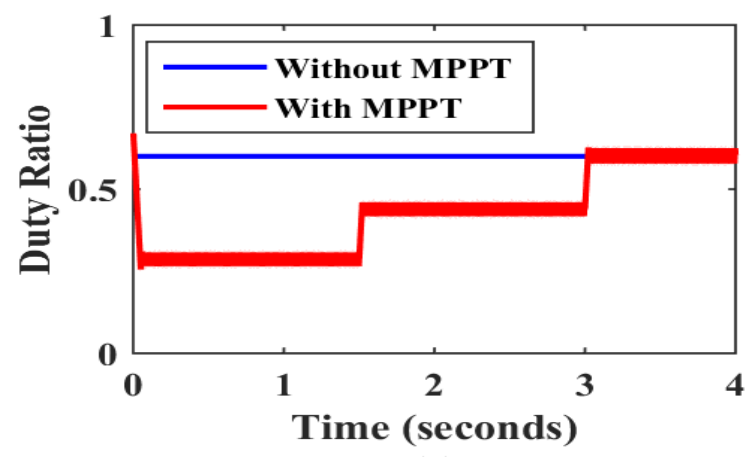

(a)

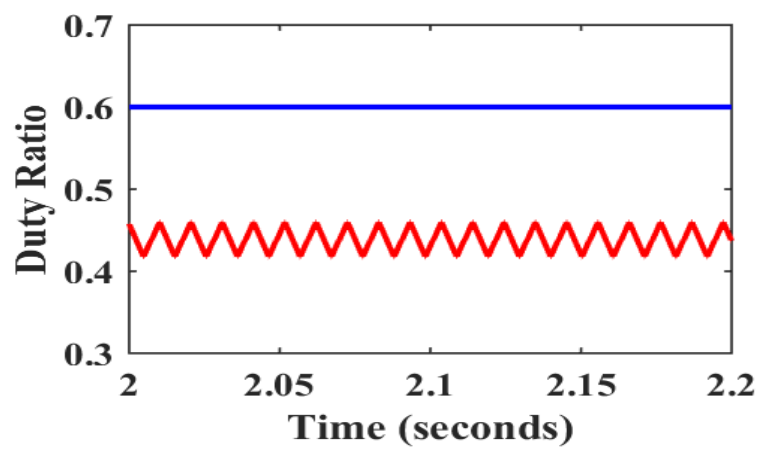

(b)

Fig.7 (a) Variation in current, voltage, power and duty ratio with and without INC algorithm for different irradiations (b) Zoomed version of the same 


\subsection{Case II : Varying temperature and} constant irradiance

The current, voltage, power and duty ratio of PV panel with and without INC controller is examined under rapidly changing temperature conditions to better understand the output variations under different temperature conditions.

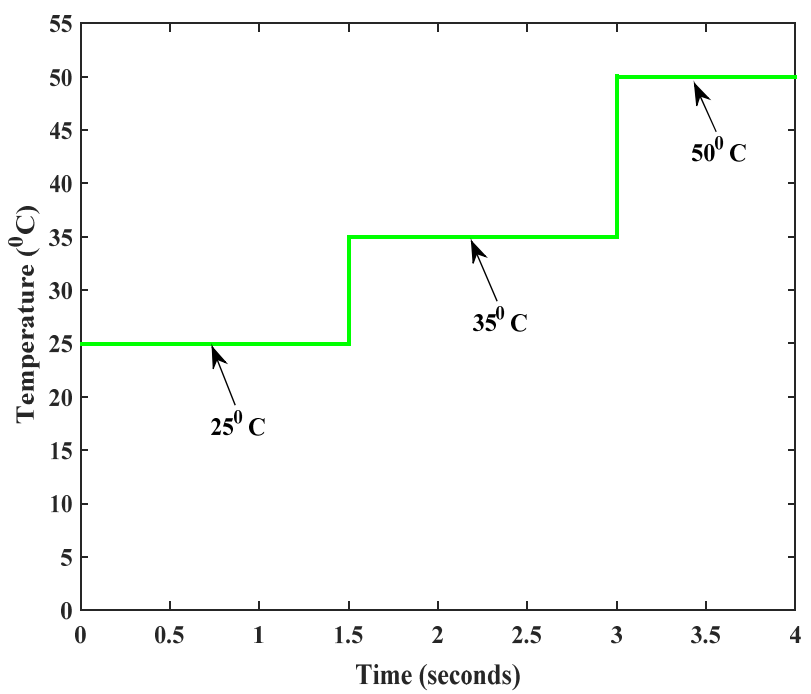

Fig.8 Variation of temperature with respect to time

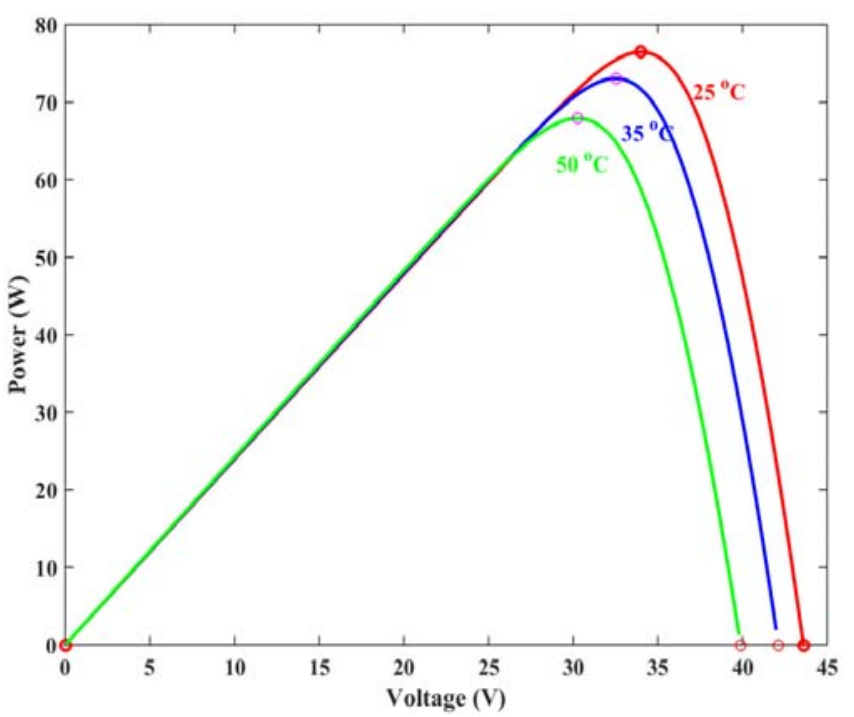

(a)
The temperature variation used in the current study is shown in Fig.8. Temperature is maintained at $250 \mathrm{C}$ from 0 to $1.5 \mathrm{~s}$. The temperature is maintained at $350 \mathrm{C}$ from 1.5 to 3 s and finally at $500 \mathrm{C}$ from 3 to 4s. In this case, at $1000 \mathrm{~W} / \mathrm{m} 2$ the irradiance intensity is kept constant. Fig.9(a) and Fig.9(b) show the P - V and I - V characteristics of the same panel at constant irradiance of $1000 \mathrm{~W} / \mathrm{m} 2$ for varying temperature. As the temperature increases, as shown in Fig.9(a), the output power is reduced. Similarly, as the temperature increases, it is clear from Fig.9(b) that the open circuit voltage of the panel is reduced. In addition, there is no significant difference in the PV panel's short circuit current as the temperature varies.

The variations in current, voltage, power and duty ratio of PV panel with various temperatures and constant irradiation of $1000 \mathrm{~W} / \mathrm{m}^{2}$ is shown in Fig. 10 . The power loss is high for a constant duty ratio of 0.6 as shown in Fig.10. With the help of INC algorithm $66.75 \mathrm{~W}$ power is obtained with a temperature of $35^{\circ} \mathrm{C}$. Without INC the power output obtained for the same condition is only $65.72 \mathrm{~W}$. The resulting output power is $78.9 \mathrm{~W}$ and $71.19 \mathrm{~W}$ respectively for a temperature of $50^{\circ} \mathrm{C}$ with and without $\mathrm{P} \& \mathrm{O}$.

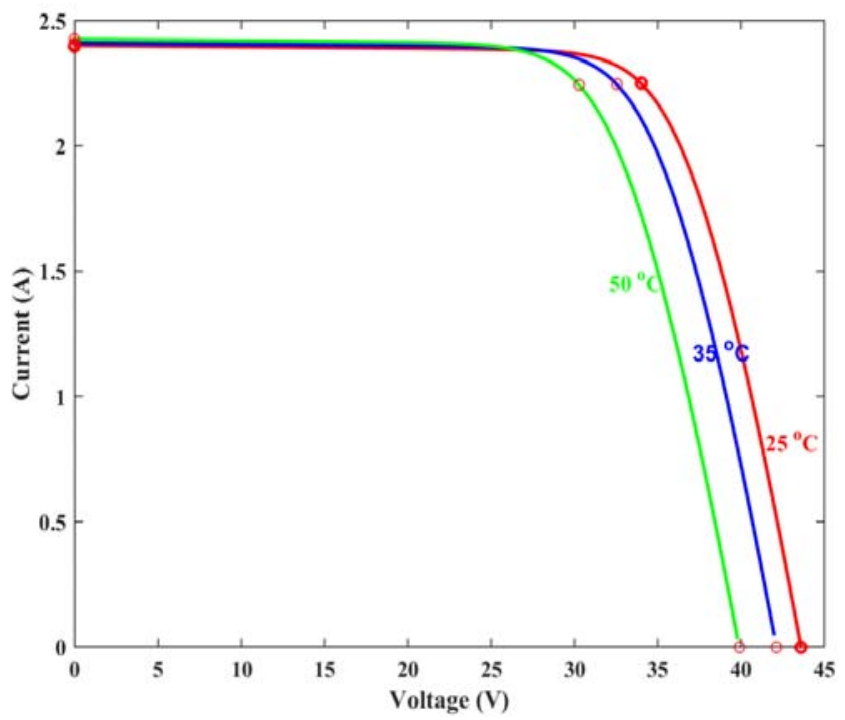

(b)

Fig.9 (a) P-V characteristics (b) I-V characteristics of PV panel at constant irradiance of $1000 \mathrm{~W} / \mathrm{m}^{2}$ and varying temperatures. 

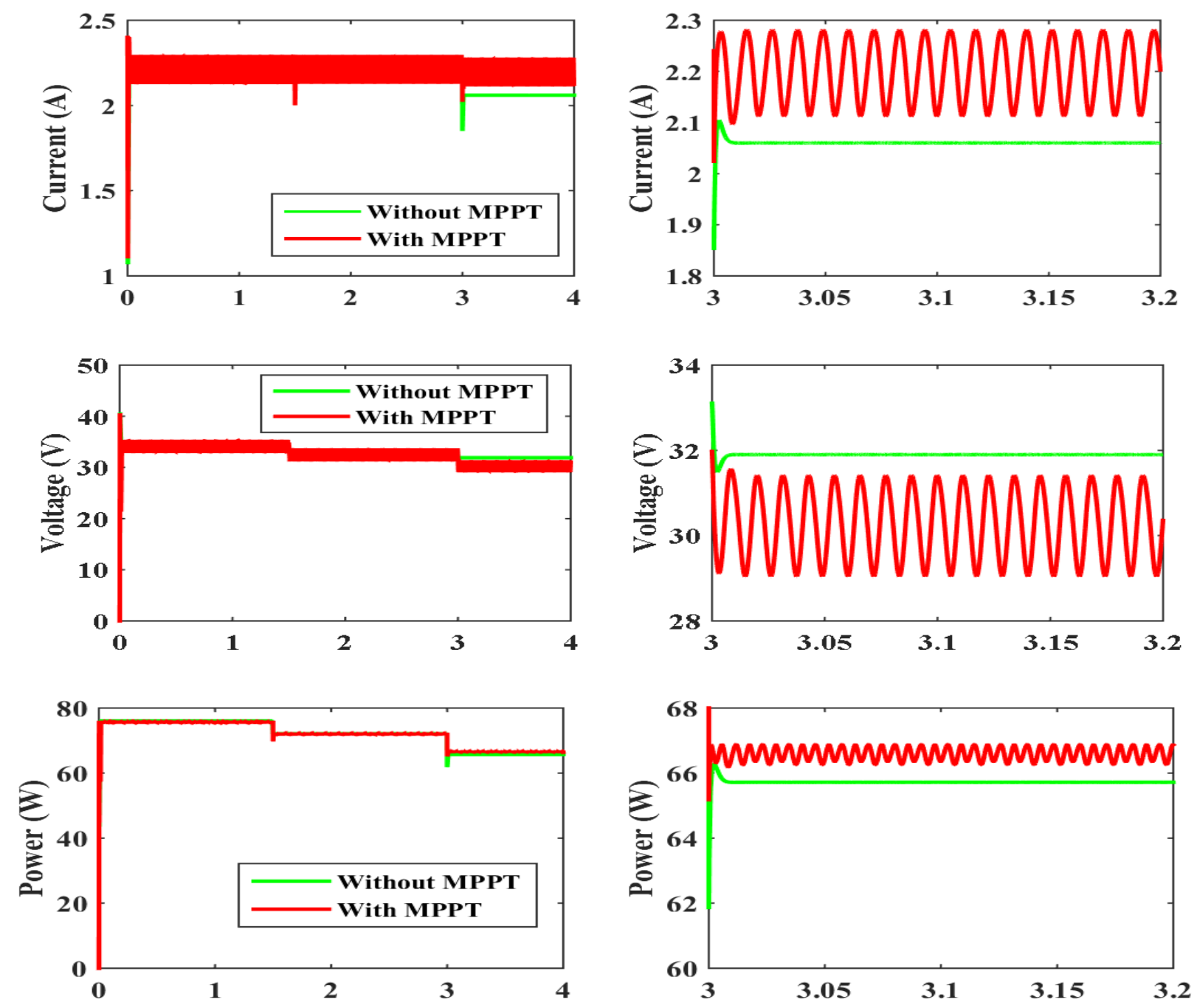

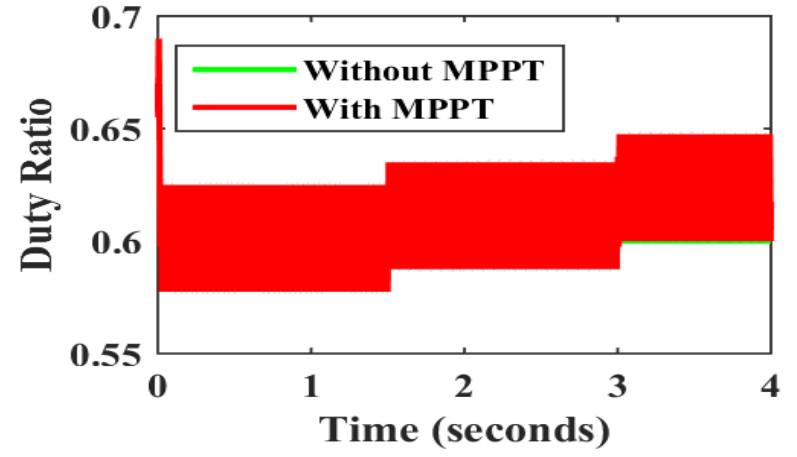

(a)

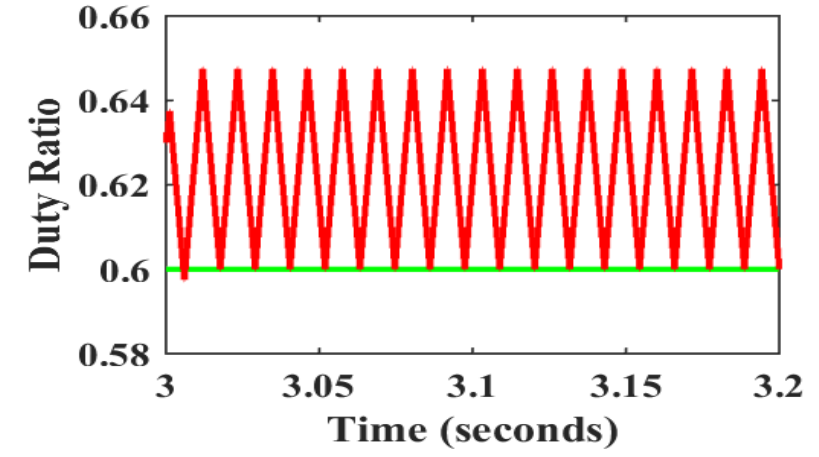

(b)

Fig.10 (a) Variation in current, voltage, power and duty ratio with and without INC algorithm for different temperatures at constant irradiance of $1000 \mathrm{~W} / \mathrm{m}^{2}(\mathrm{~b}) \mathrm{Zoomed}$ version of the same 
3.3 Case III : Continuously varying irradiance (trapezoidal input) at constant temperature

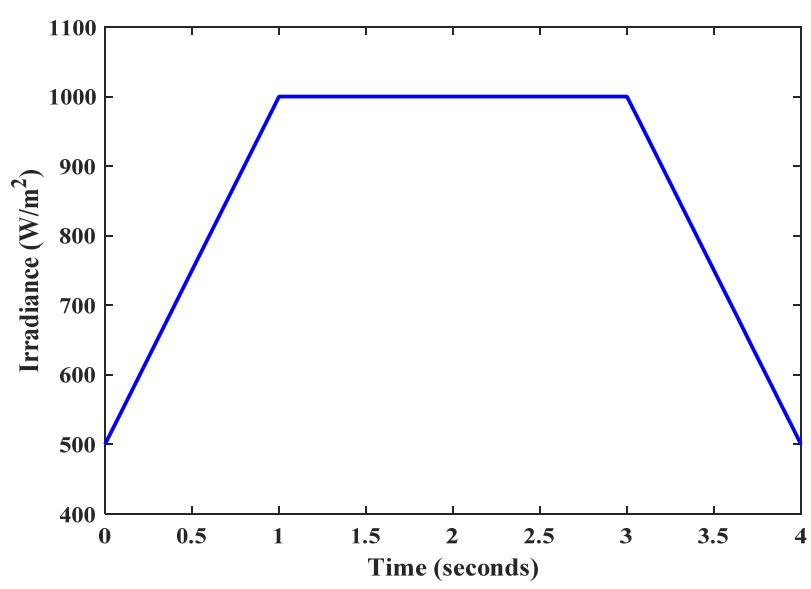

Fig.11. Irradiation changes with respect to time

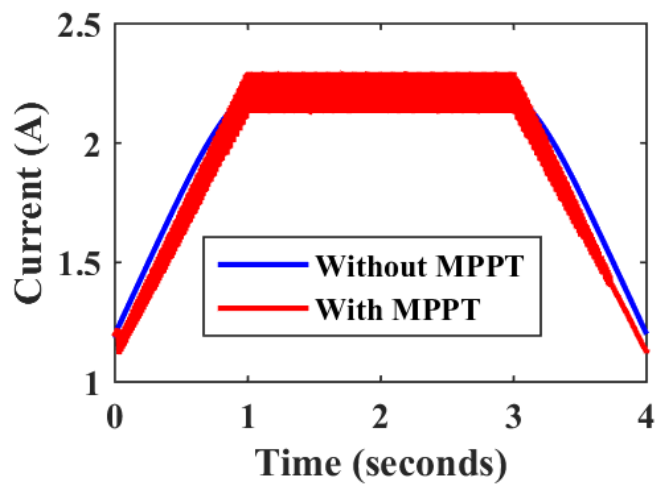

(a)

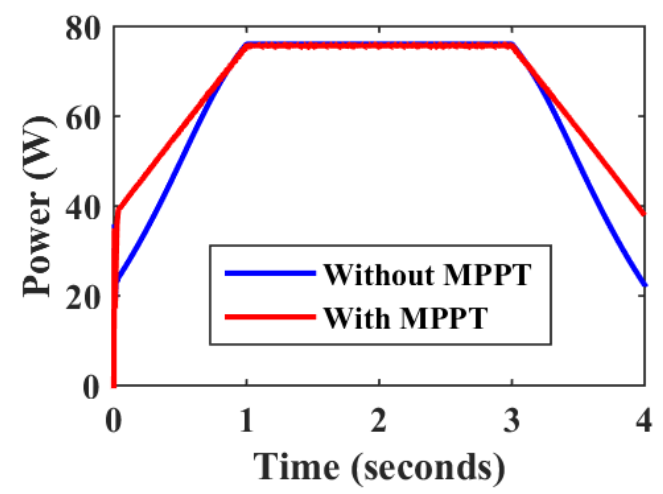

(c)
Now the simulation is done for the condition of irradiation that continually varies. A trapezoidal waveform shown in Fig.11 is used as the irradiance signal for this simulation study. The irradiance from 0 to $1 \mathrm{~s}$ linearly increases from $500 \mathrm{~W} / \mathrm{m}^{2}$ to $1000 \mathrm{~W} / \mathrm{m}^{2}$ and remains constant at $1000 \mathrm{~W} / \mathrm{m}^{2}$ to $3 \mathrm{~s}$. From 3 to $4 \mathrm{~s}$ irradiance decreases from $1000 \mathrm{~W} / \mathrm{m}^{2}$ to $500 \mathrm{~W} / \mathrm{m}^{2}$.

Fig.12 shows the variation with and without INC algorithm in the output current, voltage, power and duty ratio.

The output power varies from $75 \mathrm{~W}$ to $40 \mathrm{~W}$ for INC system when the irradiance varies from $1000 \mathrm{~W} / \mathrm{m}^{2}$ to $500 \mathrm{~W} / \mathrm{m}^{2}$. Simultaneously, the system without INC receives only about $75 \mathrm{~W}$ to $23.4 \mathrm{~W}$ output power. From these waveforms it is evident that power loss occurs for a system without an INC algorithm as the duty ratio is not adapted with the irradiation variations appropriately.

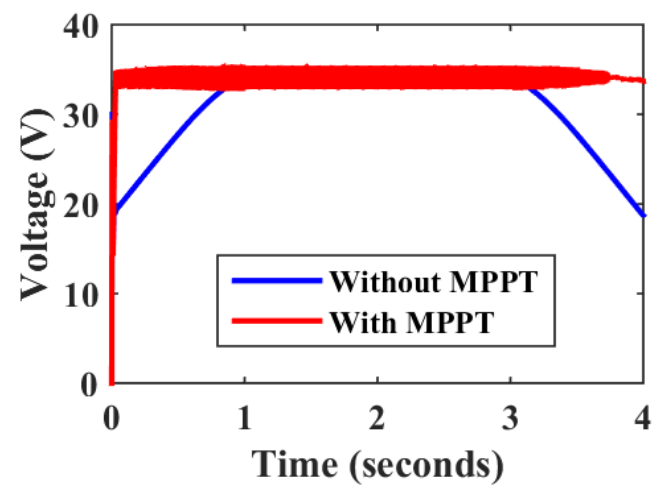

(b)

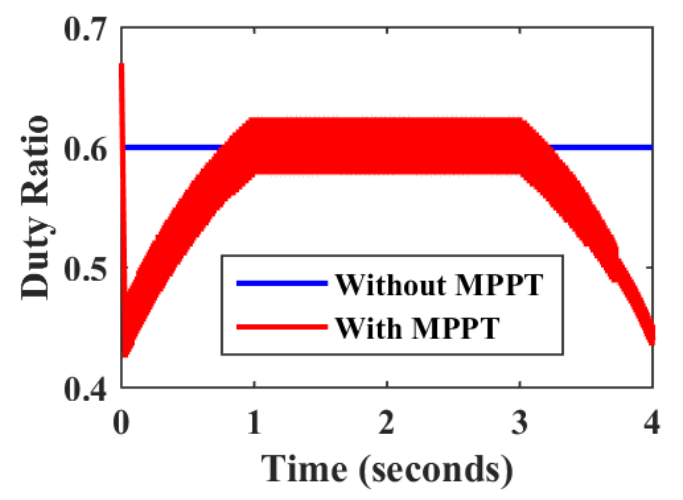

(d)

Fig.12 (a) Output current, (b) Output voltage and (c) Output power of ELDORA-75W Solar Panel for trapezoidal input irradiations and constant temperature of $25^{\circ} \mathrm{C}$ with and without INC 
3.4 Case IV: Varying irradiance (Trapezoidal input) with varying temperatures

In addition to the abrupt changes in solar irradiance, the output changes under different temperature conditions are also studied for the same system for the same trapezoidal input. These variations are shown in Fig.13 in the duty cycle, current, voltage and power output.

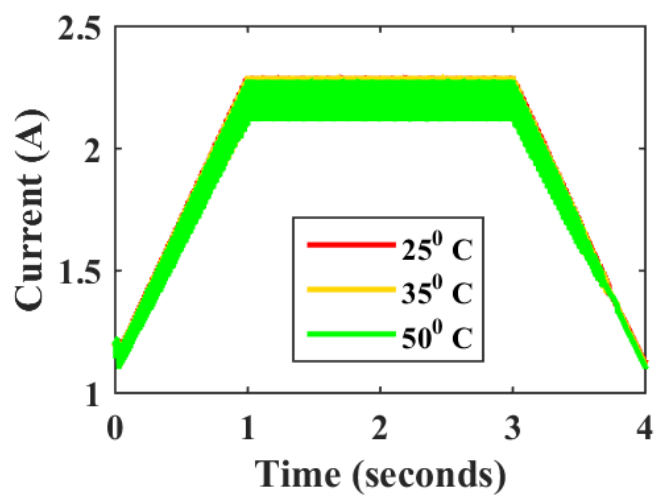

(a)

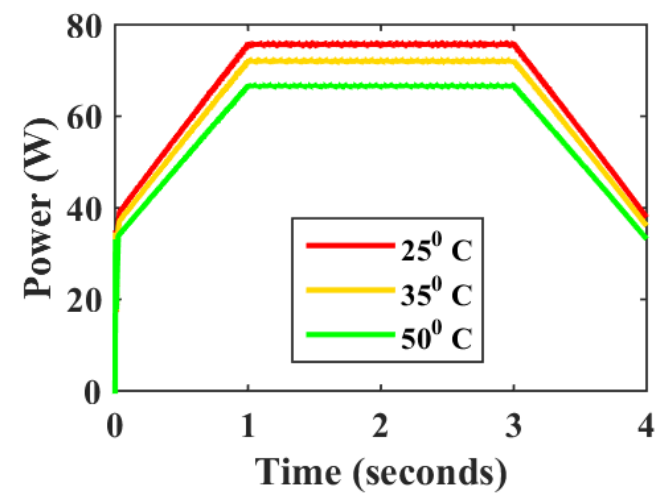

(c)
The power obtained for different temperatures of $25^{\circ} \mathrm{C}, 35^{\circ} \mathrm{C}$ and $50^{\circ} \mathrm{C}$ are $76.06 \mathrm{~W}, 72.38 \mathrm{~W}$, and $66.87 \mathrm{~W}$ respectively. From Fig.13(c) it is clear that as the temperature increases the output power decreases.

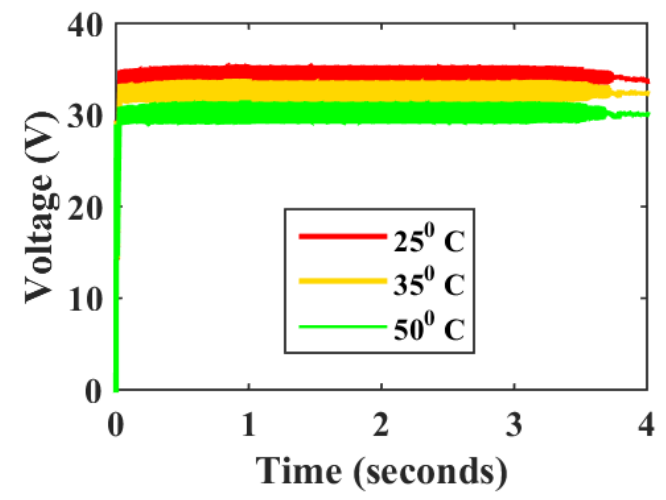

(b)

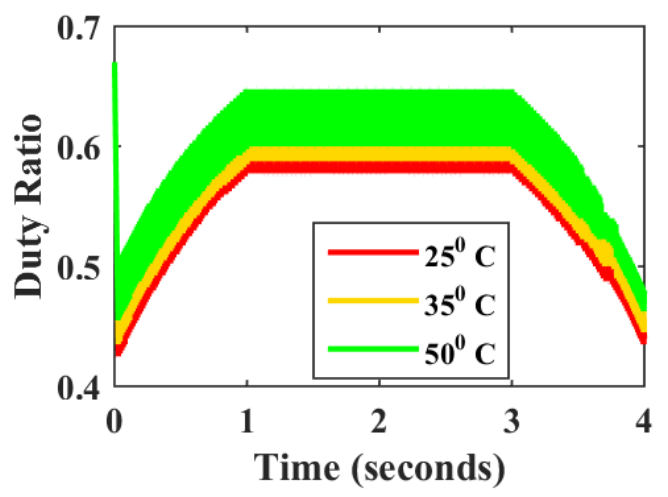

(d)

Fig.13 (a) Output current, (b) Output voltage (c) Output power and (d) Duty ratio of ELDORA_75W solar panel for trapezoidal input irradiations and different temperatures with INC algorithm 

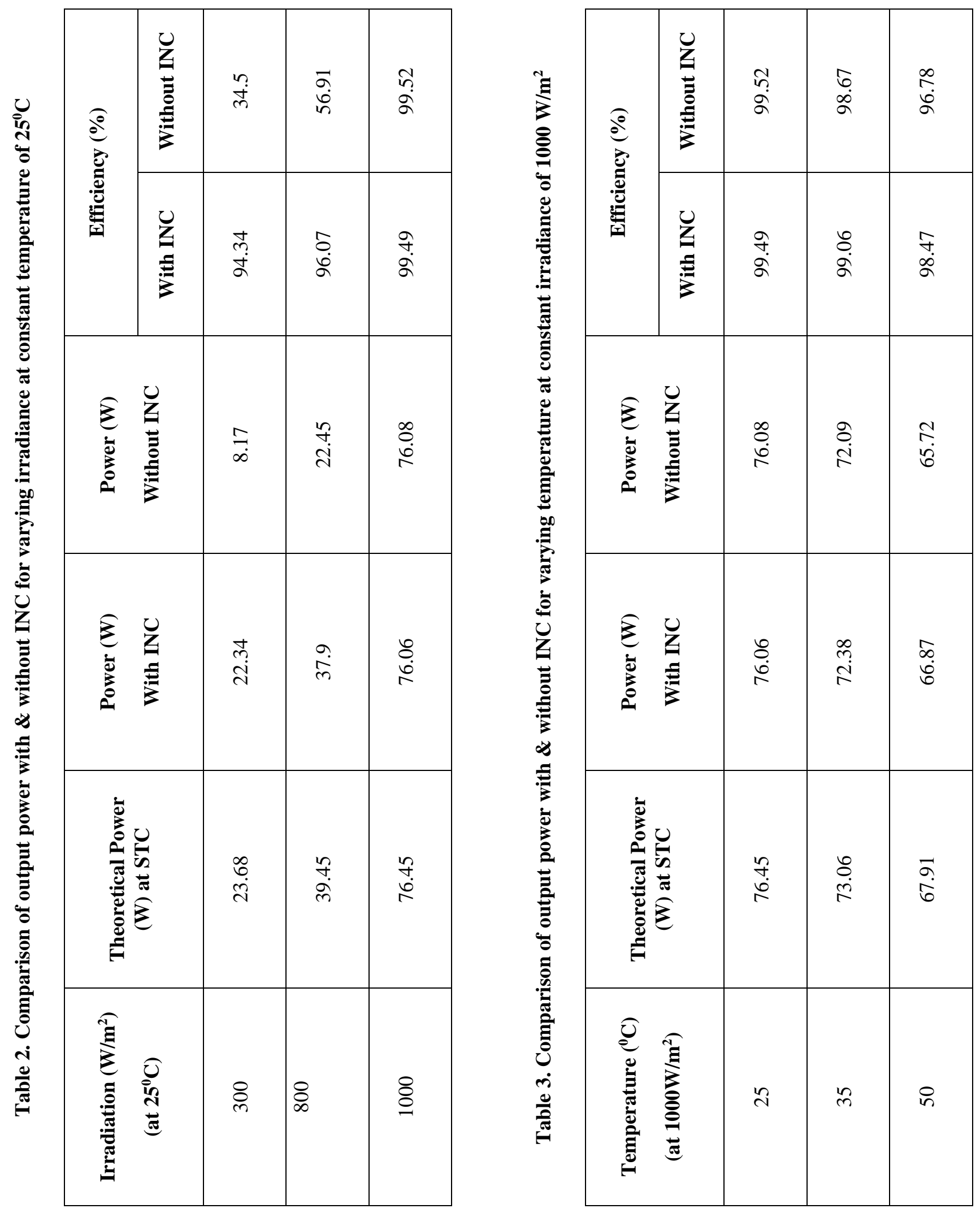
Table 2 and Table 3 provide a brief comparison of power outputs with and without INC controllers under different irradiation and temperature conditions. The theoretical values of power under different atmospheric conditions are compared with the obtained values. It is clear from this tables that the use of the INC algorithm improves the system's performance by gaining considerable power and thus improving the efficiency of the PV system.

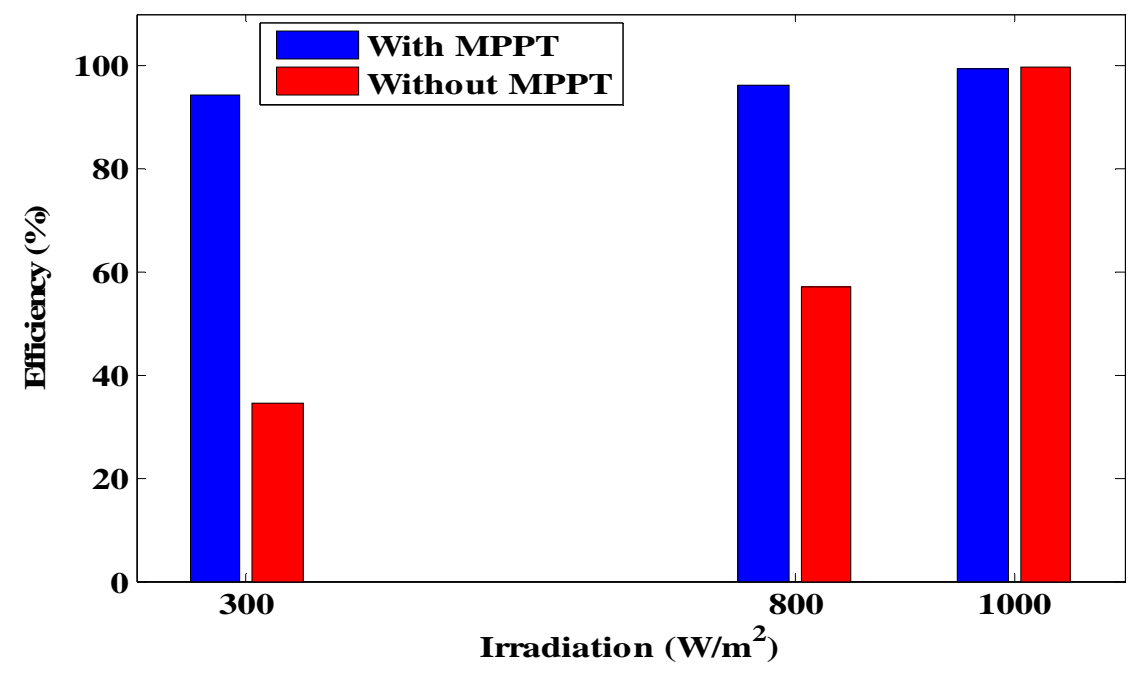

Fig.14. Bar diagram showing the efficiency of the system with and without $P \& O$ algorithm for varying irradiation

Fig.14 indicates a bar diagrams showing the PV system's efficiency with and without INC algorithm considering various irradiation conditions. From Fig.14 it can be realized that in systems without MPPT algorithm the efficiency decreases as irradiation decreases and furthermore the rapid decrease in efficiency is higher in system without MPPT.

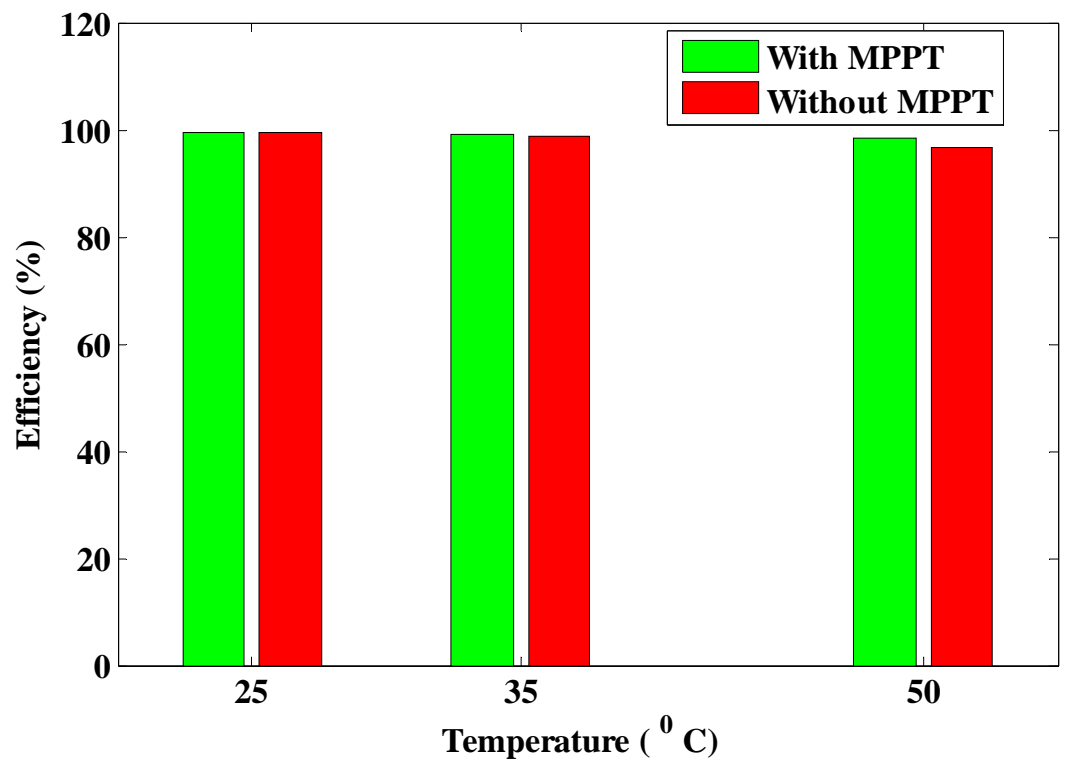

Fig.15. Bar diagram showing the efficiency of the system with and without $P \& O$ algorithm for varying temperature. 
A bar chart showing the efficiency of the PV system taking into account different temperature conditions is shown in Fig.15. From this figure it is clear that efficiency decreases as temperature increases for systems without MPPT when compared to systems with MPP for a constant duty ratio of 0.6. It is apparent from Fig.14 and Fig.15 that the efficiency is higher in systems with INC controllers compared to systems without INC controllers in all cases.

\section{Conclusion}

The importance of MPPT algorithms in the extraction of maximum power from the PV system was clearly analyzed in this paper using the INC algorithm. Modeling and simulation of a PV system with and without INC controller was presented under different weather conditions. The current study considers four different cases for irradiance as well as temperature variations. In all cases, the system efficiency with INC controller is higher than that of a system without INC. The simulation results clearly show that, in the current study, more than $40 \%$ efficiency improvement is achieved for irradiance levels around and below $800 \mathrm{~W} / \mathrm{m}^{2}$ when using an MPPT controller compared to a system without an MPPT controller using a constant duty ratio of 0.6.

\section{References}

[1] Pilakkat D. and Kanthalakshmi S.An improved $\mathrm{P} \& \mathrm{O}$ algorithm integrated with artificial bee colony for photovoltaic systems under partial shading conditions. Solar Energy, VOL.178, 2019, pp.37-47. [2] Paranthagan B. Marimuthu M. and Karthiga M.Global Maximum Power Point Tracking Under Partial Shading Condition Using SEPIC Converter. International Journal of Advanced Research in Electrical, Electronics and Instrumentation Engineering, VOL.4, NO.2. 2015, pp.718-726.

[3] Pilakkat D. and Kanthalakshmi S.Drift Free Variable Step Size Perturb and Observe MPPT Algorithm for Photovoltaic Systems Under Rapidly Increasing Insolation. Electronics Journal, VOL.22, NO.1. 2018, pp.19-26.

[4] Hussein K.H.Maximum photovoltaic power tracking: an algorithm for rapidly changing atmospheric conditions. IEE Proceedings Generation, Transmission and Distribution,
VOL.142, NO.1. 1995, pp.59.

[5] Pilakkat D. and Kanthalakshmi S.Artificial Bee Colony Algorithm for Peak Power Point Tracking of a Photovoltaic System under Partial Shading Condition. 2018 International Conference on Current Trends towards Converging Technologies (ICCTCT), 2018, pp.1-7.

[6] Yetayew T.T. Jyothsna T.R. and Kusuma G.Evaluation of Incremental conductance and Firefly algorithm for PV MPPT application under partial shade condition. 2016 IEEE 6th International Conference on Power Systems, ICPS 2016, 2016, pp.1-6. 